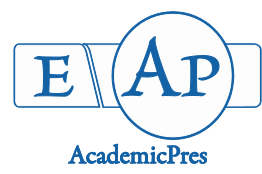

\title{
Spectrum and Frequency of Mutations Induced by Gamma Radiations in Three Varieties of Nigerian Sesame (Sesamum indicum L.)
}

\section{Muhammad Liman MUHAMMAD ${ }^{1 *}$, Ahmed Olamide FALUSI ${ }^{1}$, Matthew Omoniyi ADEBOLA ${ }^{1}$, Onyedi David OYEDUM ${ }^{2}$, Aishatu Adamu GADO ${ }^{1}$, Mohammed Chata DANGANA ${ }^{1}$}

\author{
${ }^{1}$ Federal University of Technology, Department of Plant Biology, Minna, Nigeria; \\ falusi.olamide@futminna.edu.ng; adebolamo@gmail.com;ayishatmoh@yahoo.com;ml.mubd@futminna.edu.ng(*correspondingauthor) \\ ${ }^{2}$ Federal University of Technology, Department of Physics, Minna, Nigeria
}

\begin{abstract}
Insufficient genetic variability is one of the major problems of plant breeding programmes, especially in sesame. Gamma radiation has been reported to be very effective in creating genetic variability in plants. Three varieties of Nigerian sesame were assessed for spectrum and frequency of mutation induced by Gamma radiations in $M_{1}$ and $M_{2}$ generations. The varieties (NCRIBEN-04E, NCRIBEN-01M and NCRIBEN-03L) were treated with four different doses of gamma rays $(250,350,450$ and $550 \mathrm{~Gy}$ ). The treated and untreated seeds (control) were sown in planting bags (under field condition) to raise $\mathrm{M}_{1}$ plants. Four treatments: V1D5, V2D3, V3D2 and V3D4 (from $\mathrm{M}_{1}$ plants) were selected and bulked to obtain $\mathrm{M}_{2}$ populations. The results of $\mathrm{M}_{1}$ revealed four mutant fruit traits: multicarpellate capsule, multiple capsule per leaf axil, indehiscent capsule and terminal capsules. The highest frequencies of the traits in $\mathrm{M}_{1}$ generation were $2.50 \times 10^{-2}, 9.17 \times 10^{-2}, 1.67 \times 10^{-2}$ and $3.33 \times 10^{-2}$ respectively. The highest branching (7) was from NCRIBEN-01M, while the least (2) was from NCRIBEN-04E. The $\mathrm{M}_{2}$ plants were grouped into eight $\mathrm{M}_{2}$ lines. The dose range (250-550 Gy) was proved to be effective in inducing viable mutations in sesame.
\end{abstract}

Keywords: capsule; genetic; mutants; NCRIBEN-04E; populations; variability

Abbreviations: $\mathrm{M}_{1}$ = First mutant generation; $\mathrm{M}_{2}=$ Second mutant generation; V1D5 = NCRIBEN-04E (treated with 550 Gy); V2D3 = NCRIBEN-01M (treated with 350 Gy); V3D2 = NCRIBEN-03L (treated with 250 Gy); V3D4 = NCRIBEN03L (treated with $450 \mathrm{~Gy}$ )

\section{Introduction}

Sesame (Sesamum indicum L.) is a very good source of high quality edible oil and protein food for lower class farmers in major sesame producing countries such as Sudan, Nigeria, Ethiopia, Uganda, Mexico, Venezuela, India, China, Pakistan, Turkey and Myanmar (Kumar and Yadav, 2010). The plant is also important as a source of Sesamin and sesamolin which are natural oxidants unique to its oil (Ashri, 2007).

Insufficient genetic variability has remained one of the setbacks of plant breeding programs, especially in sesame. According to Monpara (2016), the comparatively low seed yield in sesame is the key reason why sesame needs breeding to produce more yield. Cultivation of inherently low yielding varieties have been pointed as one of the factors responsible for the low average yield of sesame (Monpara, 2016).

Mutagenesis has been identified as one of the effective methods of inducing genetic variability in many crops (Wongyai et al., 2001). Through induced mutation, a large number of new cultivars have been released globally (Diouf et al., 2010) and the number of officially released mutant varieties that are recorded in FAO/IAEA reached 2,252 by the beginning of the 21 st century (Kharkwal et al., 2004). The widespread usage of induced mutants in plant breeding programs throughout the world has led to the official release of more than 2,700 plant mutant varieties (FAO, 2009).

Mutation techniques can offer a possible solution (through induced mutation) to insufficient genetic variation, a major constraint of selection and pedigree breeding. Adequate genetic diversity provides breeders with 
traits of interest. Trait-based approaches may be better in sesame breeding than yield alone, providing such yield related traits are well documented (Ranganatha et al., 2012). Monpara et al. (2008) reported that higher yields in sesame are likely to be related with increased primary branches per plant, capsules per plant and seeds per capsule.

Indehiscent capsules, superior architecture, high seed yield and resistance to diseases are amongst the basic objectives laid down for sesame breeding, which are achievable through mutation breeding (Yadava et al., 2012).

Diouf et al. (2010) studied $\mathrm{M}_{1}$ to $\mathrm{M}_{2}$ of three varieties of sesame for spectrum and frequency of induced mutation by gamma rays. They reported a wide and unique spectrum of the mutants such as branching habit, flowering types, closed capsules, capsule number and shape. Çağrgan (1996) recommended that doses 300-450 Gy should be enough for deletions to obtain closed capsules mutants. Higher doses were not advisable since lower doses produce the desired genetic changes with less primary physiological damages (Çağırgan, 2001). Van Zanten (2001) reported that from their research on several mutant generations of sesame, various characters were induced mostly affecting the capsules (CAP), flowers (F), leaves (L), maturation (MAT), male sterility (MS), plant architecture (PA) and seeds (S).

Thus the present study was designed to evaluate effectiveness of gamma ray irradiation in creating viable mutants in three sesame varieties and examine if this could be a strategy in its improvement through mutation breeding.

\section{Materials and Methods} stocks

Collection of sesame seeds and salient features of the parental

The seeds of three of varieties: NCRIBEN-04E, NCRIBEN-01M and NCRIBEN-03L were obtained from National Cereal Research Institute (NCRI) Badeggi, Niger State, Nigeria. Some salient features of the three varieties are shown in Table 1.

\section{Irradiation of the seeds}

Each of the three varieties of sesame was divided into five parts ( $5 \mathrm{~g}$ each) and exposed to gamma irradiation dose of $0,250,350,450$ and 550Gy, respectively, from Co-60 source at Centre for Energy Research and Training (CERT) Ahmadu Bello University Zaria, Kaduna State, Nigeria.

\section{Experimental site}

The field experiment was conducted at the Departmental garden, Department of Biological Sciences, Federal University of Technology, Minna, Nigeria.

\section{Experimental design and planting procedure}

The irradiated seeds alongside with their respective controls were sown in planting bags. A $3 \times 5$ factorial experiment was adopted with Randomized Complete Block Design (RCBD). The experiment had three replicates. Each replicate comprised of 60 bags with each of the 15 treatment combinations being equally represented. This gave rise to 180 bags for the whole experiment. Five seeds were planted per bags, which were later thinned to four plants at two weeks after planting (WAP). The plants were sprayed with insecticide at flowering stage as to minimize the risk of cross pollination (by insects) in the $M_{1}$ as suggested by Van Zanten (2001). Mutant frequency was estimated according to Diouf et al. (2010) by dividing total number of mutants by total number of the $M_{1}$ plants in the bulk population. The number of branches per plant were counted and recorded and were classified into single, few and many branches when the average number of branches was 1, 2-4 and $>4$ respectively. The mean values were approximated to one significant figure.

\section{Selection of $M_{2}$ parents and grouping of $M_{2}$ populations}

The $M_{1}$ plants were harvested into different treatment groups, and four treatments were selected and bulked to obtain $\mathrm{M}_{2}$ populations. Two treatments out of four were from NCRIBEN-03L (250 and 450Gy), while the other two were from NCRIBEN-01M (350) and NCRIBEN$04 \mathrm{E}(550 \mathrm{~Gy})$. The $\mathrm{M}_{2}$ individuals from the $\mathrm{M}_{2}$ parents were grouped into lines using combination of the two traits : number of carpels per capsule and capsule number per leaf axil. Each of the line was assigned a code of nine characters. The first three characters of the $\mathrm{M}_{2}$ lines came from their parental stocks' name, while the second three characters represented the irradiation dose (Gy) and the last three characters described the group number and total number of groups (lines) from the treatment.

\section{Results}

Some viable mutation from $M_{1}$ and $M_{2}$ generation

Four mutants were clearly identified from $M_{1}$ plants. These include mutants with multicarpellate capsule, multiple capsules/axil, indehiscent capsule and terminal capsules (Table 2 and Figs. 1, 2 and 3). The highest frequencies of the traits were $2.50 \times 10^{-2}, 9.17 \times 10^{-2}, 1.67 \times 10^{-}$ ${ }^{2}$ and $3.33 \times 10^{-2}$ respectively. The highest branching (7.00) was from NCRIBEN-01M, while the least (2.00) was from NCRIBEN-04E (Table 2). Both the highest frequency $\left(2.50 \times 10^{-2}\right)$ of multicarpellate capsule and least frequency $\left(8.47 \times 10^{-3}\right)$ of this trait were from NCRIBEN-04E.

Table 1. The basic agronomic traits of the three varieties used

\begin{tabular}{cccc}
\hline Agronomic traits & & Variety & \\
\hline Number of capsule/axil & NCRIBEN 04E & NCRIBEN 01M & NCRIBEN 03L \\
Number of & Multicapsular & Unicapsular & Bnicapsular \\
carpels/capsule & Bicarpellate & Bicarpellate & Mid \\
Maturity & Early & Dehiscent & Late \\
Nature of the capsule & Dehiscent & & Dehiscent \\
\hline
\end{tabular}


Similarly, NCRIBEN-04E had highest frequency $\left(9.17 \times 10^{-2}\right)$ of multicapsule per leaf axil, but the NCRIBEN$03 \mathrm{~L}$ had least $\left(2.61 \times 10^{-2}\right)$ (Table 2$)$. The highest mean number of branches (7.00) was recorded in NCRIBEN$01 \mathrm{M}$, while the least (2.00) was in NCRIBEN-04E (Table 2).
In $\mathrm{M}_{2}$ the mutants were grouped into eight lines using combination of number of capsule per leaf axil and number of carpels per capsule (Table 3). Each of NCRIBEN-04E and NCRIBEN-03L generated three lines, while the remaining two emerged from NCRIBEN-01M (Table 3).

Table 2. Spectrum and frequency of viable mutants in $M_{1}$ populations

\begin{tabular}{|c|c|c|c|c|c|}
\hline \multirow{2}{*}{ Variety/Dose (Gy) } & \multicolumn{5}{|c|}{ Traits } \\
\hline & MC/Axil & IC & MTC & TC & $\mathrm{NOB} \pm \mathrm{SE}$ \\
\hline \multicolumn{6}{|l|}{ NCRIBEN 04E } \\
\hline 0 & $5.83 \times 10^{-2}$ & - & - & $3.33 \times 10^{-2}$ & $2.00 \pm 0.31 \mathrm{a}^{* *}$ \\
\hline 250 & $9.17 \times 10^{-2}$ & $1.67 \times 10^{-2}$ & $2.50 \times 10^{-2}$ & $8.33 \times 10^{-3}$ & $5.00 \pm 0.31 a b^{* * *}$ \\
\hline 350 & $5.93 \times 10^{-2}$ & $8.48 \times 10^{-3}$ & $8.47 \times 10^{-3}$ & $8.47 \times 10^{-3}$ & $5.00 \pm 0.43 \mathrm{ab}^{* * *}$ \\
\hline 450 & $5.22 \times 10^{-2}$ & & & $1.74 \times 10^{-2}$ & $4.00 \pm 0.76 \mathrm{ab} * *$ \\
\hline 550 & $7.76 \times 10^{-2}$ & $8.62 \times 10^{-3}$ & $8.62 \times 10^{-3}$ & $8.62 \times 10^{-3}$ & $6.00 \pm 2.27 \mathrm{~b}^{* * *}$ \\
\hline \multicolumn{6}{|l|}{ NCRIBEN 01M } \\
\hline 0 & - & - & - & - & $4.00 \pm 0.63 \mathrm{ab}^{* *}$ \\
\hline 250 & - & - & - & $8.55 \times 10^{-3}$ & $6.00 \pm 1.59 \mathrm{~b}^{* * *}$ \\
\hline 350 & $9.24 \times 10^{-2}$ & $8.55 \times 10^{-3}$ & $8.55 \times 10^{-3}$ & $8.55 \times 10^{-3}$ & $7.00 \pm 1.33 \mathrm{~b}^{* * *}$ \\
\hline 450 & - & - & $8.55 \times 10^{-3}$ & $8.55 \times 10^{-3}$ & $4.00 \pm 0.54 a b^{* *}$ \\
\hline 550 & - & - & - & - & $6.00 \pm 1.06 \mathrm{~b}^{* * *}$ \\
\hline \multicolumn{6}{|l|}{ NCRIBEN 03L } \\
\hline 0 & - & - & - & $8.40 \times 10^{-3}$ & $5.00 \pm 1.34 a b^{* * *}$ \\
\hline 250 & $2.61 \times 10^{-2}$ & $8.69 \times 10^{-3}$ & $8.70 \times 10^{-3}$ & - & $5.00 \pm 1.03 a b^{* * *}$ \\
\hline 350 & $2.63 \times 10^{-2}$ & $8.77 \times 10^{-3}$ & & & $5.00 \pm 0.40 \mathrm{ab}^{* * *}$ \\
\hline 450 & $9.00 \times 10^{-2}$ & - & - & - & $4.00 \pm 0.37 \mathrm{ab}^{* *}$ \\
\hline 550 & $9.00 \times 10^{-2}$ & - & - & - & $5.00 \pm 1.58 \mathrm{ab}^{* * *}$ \\
\hline
\end{tabular}

-No mutant recorded, $\mathrm{MC}=$ Multicapsule, $\mathrm{IC}=$ Indehiscent capsule, $\mathrm{MTC}=$ Multicarpellate capsule, $\mathrm{TC}=\mathrm{Terminal}$ capsule, $\mathrm{NOB}=\mathrm{Number}$ of branches, ${ }^{* *}$ few branching, ${ }^{* * *}$ Many branching

Table 3. The parental stock and main characters of $\mathrm{M}_{2}$ lines

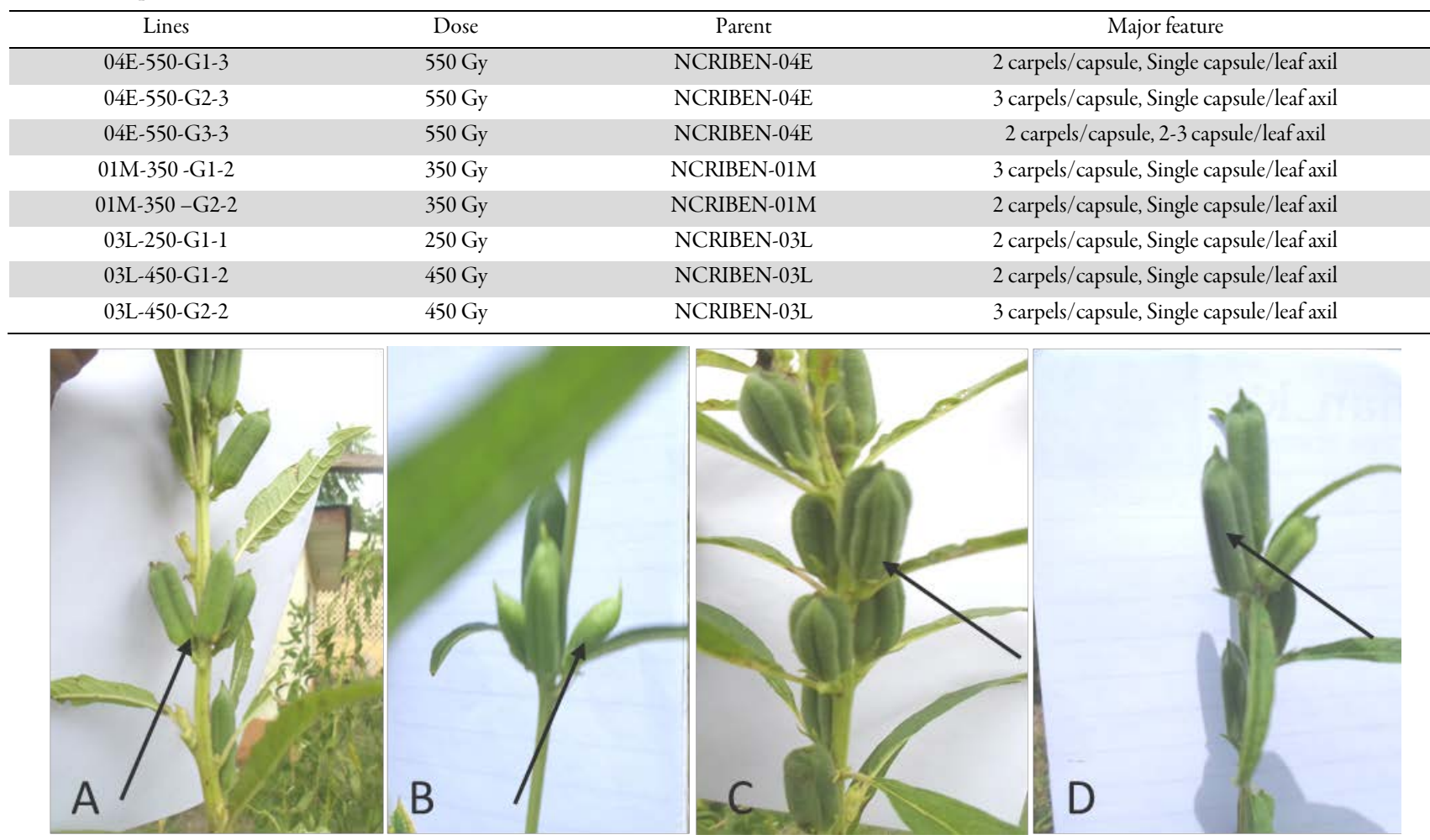

Fig. 1. Mutants from NCRIBEN-04E and control (untreated); $A=$ control with multiple capsule at leaf axil and bicarpellate; $B=$ a mutants with multiple capsules at leaf axil and indehiscent capsule; $\mathrm{C}=$ a mutants with tricarpellate capsule; $\mathrm{D}=\mathrm{a}$ mutant with terminal capsule 

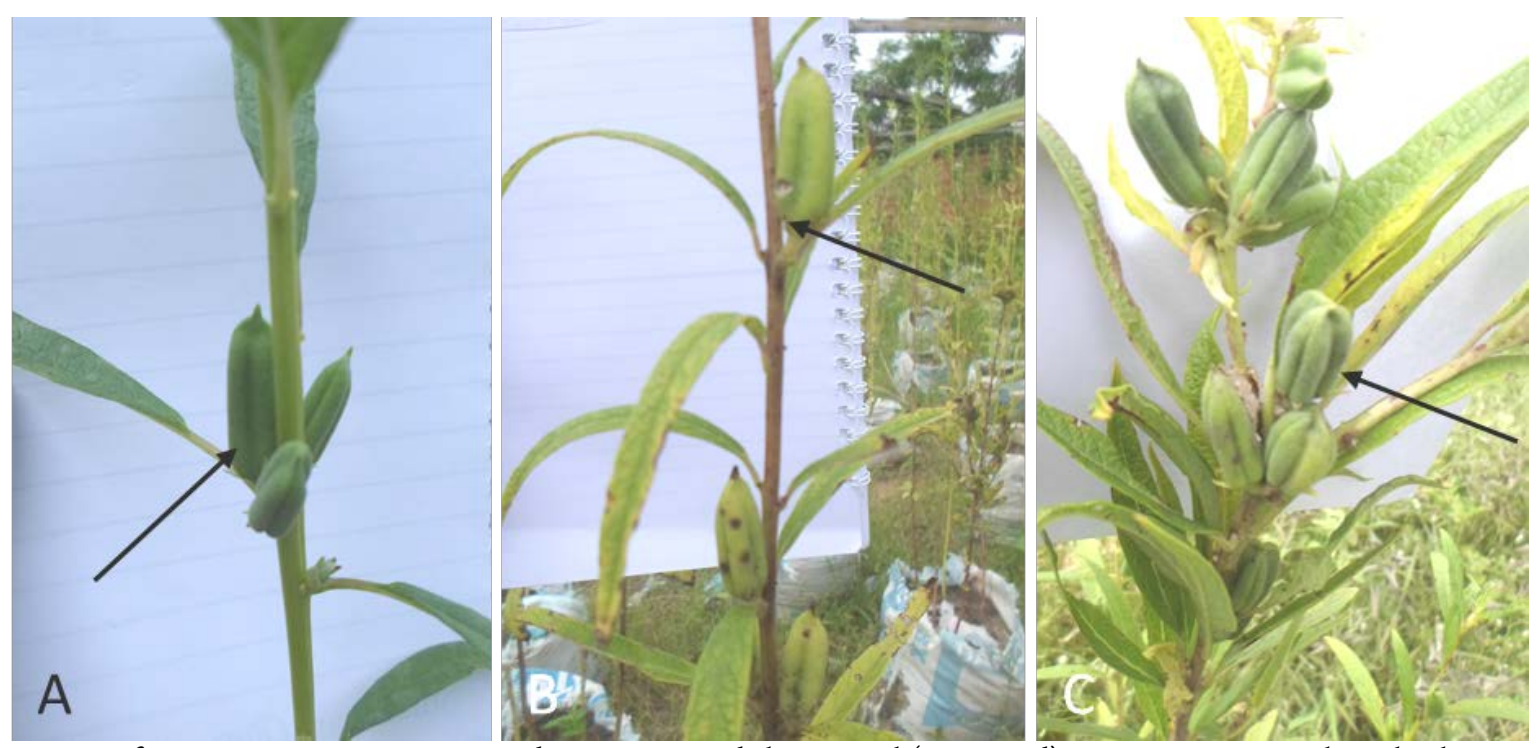

Fig. 2. Mutants from NCRIBEN-01M exposed to $350 \mathrm{~Gy}$ and the control (untreated); $\mathrm{A}=\mathrm{a}$ mutants with multiple capsules at leaf axil and bicarpellate; $\mathrm{B}=$ control with single capsule at leaf axil and bicarpellate; $\mathrm{C}=\mathrm{a}$ mutants with multiple capsules at leaf axil and tricarpellate
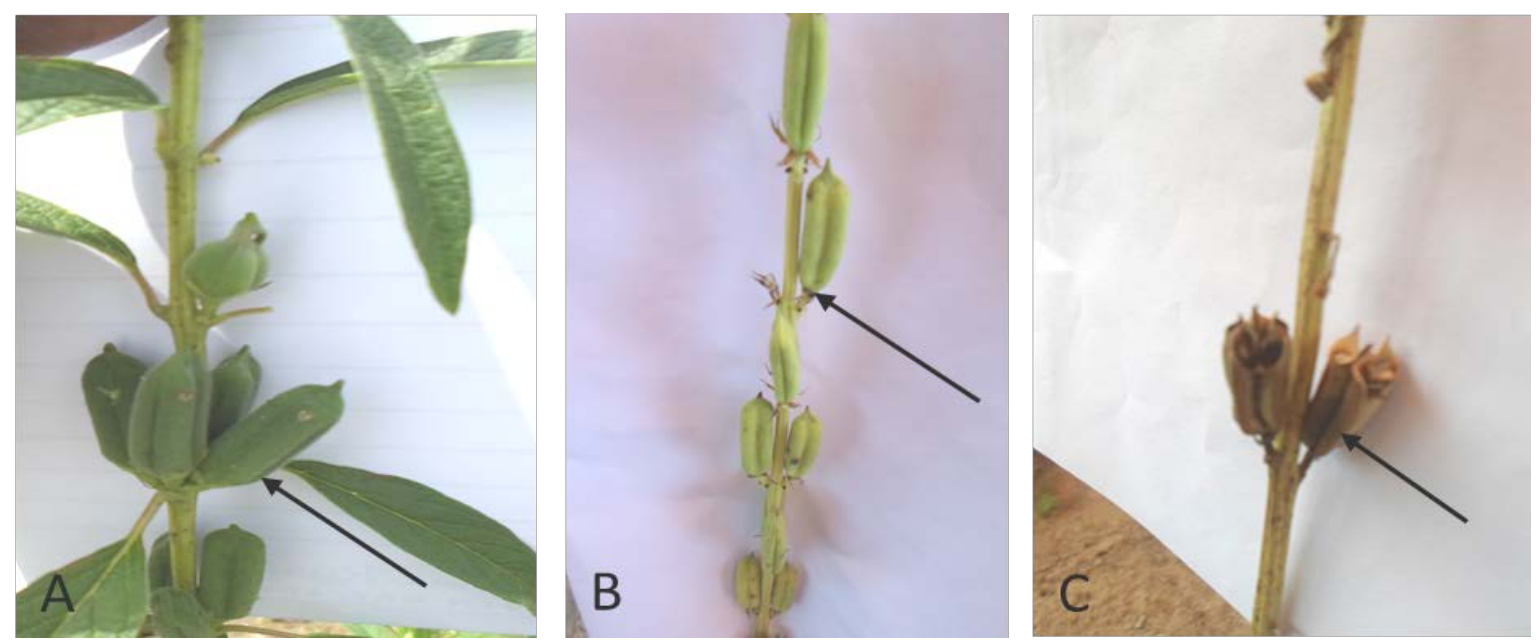

Fig. 3. Mutants from NCRIBEN-03L at $450 \mathrm{~Gy}$ and the control (untreated); $\mathrm{A}=\mathrm{a}$ mutants with multiple capsules at leaf axil; B $=$ control with single capsule at leaf axil; $\mathrm{C}=\mathrm{a}$ mutant with tricarpellate capsule

\section{Discussion}

\section{Multicarpellate capsule and multiple capsule/axil}

The frequencies recorded for the two traits imply the possibility of developing mutant with higher yield. Developing lines with increased number of carpels and/or capsule can lead to significant increase in seed yield of the plant. This observation can be corroborated by earlier reports of Diouf et al. (2010), Langham (2007), Baydar (2005). They all supported that in selection for mutants with potential high yielding; mutants with higher number of carpels/capsule are inevitable. In fact, Baydar (2005) reported a link between qudricarpels, tricapsule/leaf axil and uniculm with high oil content.

\section{Indehiscent capsule and terminal capsules}

The indehiscent capsules were small in size, with fewer number of seeds. These attributes can disqualify the mutants during selection as they are linked with low yield. Langham (2001) reported the indehiscent mutant is controlled monogenically and the homozygous recessive (id/id) gave indehiscence. However, the id allele had pleiotropic effects including cupped leaves, twisted stems, short seed pods, semi-sterility and low yield. The mutants with terminal capsules can help reduce or solve the problem of non-synchronous capsule maturation in sesame especially. This is due to indeterminate growth habit which is a common phenomenon in most sesame cultivars.

\section{Branching habit and single capsule/ leaf axil}

The mutants from the three varieties were categorised by branching characteristics ("few" or "many") and they might be good mutants for selection. Earlier reports from Monpara et al. (2008), Van Zanten (2001), Beech and Imrie (2001) supported the view that with branching habit is good mutants for selection. Monpara (2016) observed that higher yields in sesame are likely related or associated with higher number of primary branches per plant. Such association can support use of branching habit as one of the criteria for selection. 
Zanten (2001) reported that from long time research on sesame, plant architecture was a frequently selected character in mutant sesame lines, including short internode length, profuse branching, uniculms and semi-dwarfs. Beech and Imrie (2001) reported that for mechanised harvest mutants with shorter stature and branched habit are preferable. They also stated that plants with branching habit generally have smaller stem diameter and are easier to cut than those of uniculm plants.

The single capsule/leaf axil which is common to most of the $\mathrm{M}_{2}$ lines has also been reported as one of the traits used in selection of sesame mutants. According to Beech and Imrie (2001), the criteria for selection of sesame cultivar (in term of capsule) for mechanisation, include, single capsule per leaf axil, long narrow capsule with deep indent at top, synchronous maturation and good seed retention.

\section{Conclusions}

The results of the present research proved that the radiation dose range of 250-550 Gy was effective for viable mutation in sesame. Thus, the $\mathrm{M}_{2}$ lines should be advanced to $\mathrm{M}_{3}$ and $\mathrm{M}_{4}$ for confirmation of the identified mutants.

\section{References}

Ashri A (2007). Sesame (Sesamum indicum L.). In: Singh RJ (Ed). Genetic Resources, Chromosome Engineering and Crop Improvement 4:231289.

Baydar H (2005). Breeding for the improvement of the ideal plant type of sesame. Plant Breeding 124:263-267.

Beech DF, Imrie BC (2001). Breeding for mechanised sesame production in Australia. Joint FAO/LAEA Division of Nuclear Techniques, in Food and Agriculture, International Atomic Energy Agency, Vienna (Austria) pp 63-70.

Çağrgan MǴ (1996). Radiosensitivity of Turkish sesame cultivars to gamma-rays. Turkish Journal of Field Crops 1(2):39-43.

Çağırgan MG் (2001). Mutation techniques in sesame (Sesamum indicum L.) for intensive management: Confirmed mutants. In: Sesame improvement by induced mutations. IAEA-TECDOC-1195, IAEA, Vienna(Austria) pp 31-40.

Diouf M, BoureimaS, Diop T, Çağirgan MǴ (2010). Gamma rays-induced mutant spectrum and frequency in sesame. Turkish Journal of Field Crops 15(1):99-105.
Food and Agricultural Organization (FAO) (2009). Induced plant mutations in the genomic era. Publication of the Food and Agricultural Organization of the United Nation (FAO) Rome.

Kharkwal MC, Pandey RN, Pawar SE (2004). Mutation breeding for crop improvement. In: HK Jain, MC Kharkwal (Eds). Plant breeding. Mendelian to molecular approaches. Narosa publishing house, New Delhi, Indiapp 601-645.

Kumar G, Yadav RS (2010). EMS induced genomic disorders in sesame (Sesamum indicum L). Romanian Journal of Biology - Plant Biology 55(2):97-104.

Langham DR (2001). Shatter resistance in sesame. Joint FAO/LAEA Division of Nuclear Techniques, in Food and Agriculture, International Atomic Energy Agency, SESACO Corporation San Antonio, Texas, United States of America.

Langham DR (2007). Phenology of sesame. In: Janick J, Whipkey A (Eds). Issues in new crops and new uses.. ASHS, Press, Alexandria, VA pp 144 182.

Monpara BA, Vora MD, Chovatiya BM, Radadia BV (2008). G. Til 3: A white and bold seeded sesame variety for Saurashtra region of Gujarat. Journal ofOilseeds Research 25(2):186-187.

Monpara BA (2016). Sesame germplasm evaluation for reproductive period and harvest index. Genetika 48(2):665-674.

Ranganatha ARG, Lokesha R, Tripathi A, Tabassum A, Paroha S, Shrivastava MK (2012). Sesame improvement- present status and future strategies. Journal of Oilseed Research 29(1):1-26.

Van Zanten L (2001). Sesame improvement by induced mutations. Plant Breeding and Genetics Section, Joint FAO/LAEA Division of Nuclear Techniques, in Food and Agriculture, International Atomic Energy Agency, Vienna (Austria) pp 2-12.

Wongyai W, Saengkaewsook W, Veerawudh J (2001). Sesame mutation induction: Improvement of non-shattering capsule by using gamma rays and ems. Report Joint FAO/LAEA Division of Nuclear Techniques in Food and Agriculture, Vienna(Austria) pp 71-78.

Yadava DK, Vasudev S, Singh N, Mohaptra T, Prabhu KV (2012). Breeding major oil crops: Present status and future research needs. In: Technological Innovations in Major World Oil Crops. Springer, New York, NY,Volume 1 pp 17-51. 